\title{
Research on Network Visual Marketing Strategy of Garment Enterprises
}

\author{
Yuanyuan Zhang; Zhixiang Wang \\ School of Art \& Clothing, Tianjin Polytechnic University \\ No. 399, Bin Shui Xi Dao, Xiqing District, Tianjin City, China
}

\begin{abstract}
With the global popularization of ecommerce, the sales methods of garment enterprises have started developing from the traditional entity stores to the orientation of network sales, and network marketing launches enterprises' multiple marketing patterns. Based on the deficiency that online shopping is devoid of a sense of reality, when promoting the website construction, China's garment enterprises should also intensify the development of and the research on online commodity exhibition technology and visual marketing strategy, so as to create the optimal shopping environment similar to traditional sales environment.
\end{abstract}

Key words: Garment Enterprises; Network; Visual Marketing; Strategy

\section{Network Visual Marketing- the Brand New Way to Supplement Added Value for Enterprises}

National Retail Federation Convention has made the following definition for visual marketing: visual marketing exists to achieve the objective of marketing, and it is a method that combines exhibition technique and visual presentation technique with the marketing of commodities by making joint efforts with the purchasing department to provide commodities to the market for display selling. Visual marketing is not only an important strategy for enterprises' clothing brands pro- motion, but also an important element that is carried out throughout the clothing marketing. The emergence of network visual marketing is mainly based on the increasingly fiery online consumption activities. With the enlargement of the size of online consumption activities and the aggravation of the brand competitiveness of domestic clothing industry, the overall development of brands appears to be of essence. As the brand new way to supplement added value for enterprises, the strategy of network visual market provides comprehensive solutions for enterprises' network operation, which helps enterprises gain more sales profits and expand their brand influence. Under the background of online consumption, only the network visual marketing method in accordance with the consumer shopping behavior can arouse shoppers' desire to purchase, so that it can increase the sales volume, bring profits to enterprises' network marketing sales behavior, and really become the brand new way to supplement added value for enterprises.

The big difference of online shopping from physical store shopping is that purchasers can browse the website at their own will and buy whatever goods they want by keeping indoors, which is both time and effort saving. To make network visual marketing become enterprises' brand new way to supplement their added value, there must be some strategic approaches. The top priority of visual marketing is to attract browsers to remain on the display pages for longer 
time or arouse their interest in commodities, so that they can be willing to collect this website and browse it again next time. Only in this way can an ordinary website browser be turned into a purchaser who can bring profits.

\section{Analysis of the Strategy of Creating Consumer Value}

Enterprises' network marketing activity refers to the online commodity transaction activity by making use of electronic communication technology, basing on $4 \mathrm{C}$ marketing mode, and emphasizing customer orientation. In network transaction activities, consumers' loyalty and satisfaction is the fundamental force for the survival and development of online sellers. Thus, creating customer value to the maximum limit is the important content of network marketing activities. In network transaction activities, consumers mainly learn of the products and service information, contact the company's customer service and after-sale personnel, and know about the demand of the whole marketing process. Customers who participate in network marketing activities are of significant consumption characteristics, the most obvious of which include the individuation of consumption, the diversity of demand and the initiative of consumption. In the meantime, their demand for shopping convenience, pursuit of shopping enjoyment, and requirement for shopping environment are constantly strengthening. The influence of enterprises' network visual marketing activities on the customer value is reflected in two aspects, i.e. when it is in favor of creating and achieving customer value, it also plays a role of reducing some original customer value of an enterprise and increasing difficulty for the enterprise to build the customer value advantage to a certain extent. Based on profoundly analyzing the customer demand and con- sumption characteristics, enterprises should pay attention to discover potential customer value, focus on developing the potential of Internet service marketing, fully make use of the means of two-way interaction with customers, intensify exchange and communication with customers, and effectively integrate and optimize its network visual marketing activity, so as achieve the objective of promoting customer value.

\section{Effective Strategies of Garment En- terprises' Network Visual Marketing}

\subsection{The Display Manner of Clothing Commodities}

Most clothing commodities are displayed by fashion models, and only a few commodities are displayed in tiled way. When displaying clothing online, if by the means of plane presentation, it will be difficult for customers to clearly see the contour line of clothing and experience the three-dimensional impression. Compared with other commodities, clothing commodities are of stronger fashion element, thus, displaying them by models with fashion sense can not only let consumers learn of the appearance of clothing, but also give a picturesque illustration about the fashion attitude and the fashion property possessed by commodities, in which way, it will be convenient for consumers to select commodities according to their demand.

\subsection{The Technique of Commodities Display}

In nowadays China's online clothing marketing enterprises, only a tiny minority of them carries out the effect presentation from different angles, and a majority of them fails to adopt 3D rotation technique but remains in the scope of $2 \mathrm{D}$ display. It is very essential to develop visual display technique to observe the clothing, 
only in which way can customers inspect the clothing from any angle, can they remove their worry about the uncertain information related to the clothing, and can they increase the possibility of promoting the final transaction. For instance, if most parts of a displayed picture can be amplified and some specified sections among them can be amplified, it will help consumers obtain information about the clothing more accurately. At present, there have been some $3 \mathrm{D}$ production companies in China, who apply computer technique and adopt the omnibearing interactive viewing means to display the real scene, which will be more beneficial to reveal the details and achieve the 3D effect of clothing.

\subsection{Supplementary Display of Clothing}

Color is an important element of clothing commodities. Investigation has found that nearly one-third online shoppers would refuse to purchase a clothing commodity due to the color problem displayed. Nearly half of online franchisers fail to describe the color of a commodity or describe it ambiguously, so consumers can only make a judgment from the displayed pictures. In domestic garment enterprises, almost few of them display the same commodity with different sizes by figure models. In fact, in the course of online shopping, consumers concern much about the color and size of a commodity. Since they cannot try on for comparison like in physical stores, it is necessary to give a description about the detailed and accurate size, and it's better to provide virtual try-on of different body forms, so that consumers can input the size in accordance with their own body forms to establish a model similar to their body forms. This form is closer to the shopping environment of physical stores and can improve consumers' knowledge of products. In the process of shopping, customers would always give up purchasing a commodity due a detail failure. In order to draw more customers' attention, dealers should provide more details display of a commodity, such as its material, the structure of the collar, the design of the pocket, the color and style of the button, etc. It's better to also provide accessories corresponding to the commodity as well as their convenient links. To obtain artistic effect of clothing network marketing, the focus on details of a commodity must be increased.

\subsection{The Quantity and Position of the Pictures to be Displayed}

Nowadays, the quantity of the display pictures of most clothing commodities is between 4 and 6 . There is only a minority of commodities with more than 6 display pictures. Regarding commodities with more than 6 display pictures, they basically provide consumers with color and details display of commodities mentioned above. Based on human eyes' sensitive perception of colors, when shoppers browse the website, they would be more inclined to look for colorful pictorial information. Rational coordination between pictures display and words description can help consumers with information acceptance and handling, so as to deepen their knowledge of all parts of a clothing commodity. Besides, when observing things, people's eyes are accustomed to look from left to right and from up to down, therefore, when designing the commodity display, it's better to locate major commodities at the upper-left page, which is in accordance with online browsers' browsing habit. Some online dealers display commodities in the middle of the webpage, and only a minority of them locate commodities at the right side; however, with appropriate integral planning and reasonable proportion of the webpage, the unique display effect can also be achieved. 


\section{References:}

[1] Pengzhi Qu. Network Marketing. [M]. Beijing: Higher Education Press, 2001: 56- 95.

[2] Chunxiang Luo. How to Improve the Customer Value of B2C E-commerce [J]. Enterprise Economy, 2005(4): 12.

[3] Xiaohui Li. Fashion Visual Merchandising [M]. Beijing: China Textile Press, 2008: 4.
[4] Yang Han. Stores Display DesignActual Combat Training of Fashion Visual Merchandising [M]. Beijing: China Textile Press, 2006: 3.

[5] Wei Cong, Liying Zhou. Analysis of Visual Marketing Strategy of Domestic Clothing Brands [J]. Journal of Northwest University: Philosophy and Social Science Edition, 2010(1): 1'3 